\title{
Die elementaren (Fremd-)Erfahrungen der Gabe
}

\section{Sozialtheoretische Implikationen von Marcel Mauss' \\ Kultursoziologie der Besessenheit und des ,radikalen Durkheimismus" des Collège de Sociologie}

\section{Stephan Moebius}

\section{Erratum zu: Berlin J Soziol (2009) 19:110-112, 116, 121 DOI 10.1007/s11609-009-0050-y}

Bedauerlicherweise sind aufgrund von Kürzungen im ursprünglichen Fußnotenapparat meines Aufsatzes „Die elementaren (Fremd-)Erfahrungen der Gabe“ (Berliner Journal für Soziologie, Heft 1/2009) im Abschnitt zu Marcel Mauss Verweise weggefallen. Auf den Seiten 110-112, 116 und 121 meines Aufsatzes greife ich auf Überlegungen, Begriffe und Formulierungen zurück, die Iris Därmann in ihrem unveröffentlichten Buchmanuskript „Im Zeichen der Gabe. Kulturtheorien von Mauss bis Serres“ entwickelt hat. Bei dem Text der Fußnote 22 handelt es sich von Zeile eins bis vier um ein wörtliches Zitat aus einer von Iris Därmann formulierten Passage eines gemeinsam eingereichten Antragstextes bei der Thyssen-Stiftung.

(C) VS-Verlag 2009

Die Onlineversion des Originalbeitrages ist erreichbar unter doi: 10.1007/s11609-009-0050-y

S. Moebius $(\bowtie)$

Abteilung für Soziologische Theorie und Ideengeschichte, Institut für Soziologie Karl-Franzens-Universität Graz, Universitätsstraße 15/G4, 8010 Graz, Österreich E-Mail: stephan.moebius@uni-erfurt.de 